\title{
Developing the sector of remote services in rural areas to raise the employment and care of the environment
}

\author{
Aleksey Parshukov ${ }^{1}$, Igor Aleksandrov ${ }^{1, *}$, and Marina Fedorova ${ }^{2}$ \\ ${ }^{1}$ Peter the Great St.Petersburg Polytechnic University (SPbPU), Polytechnicheskaya 29, 195251, St. \\ Petersburg, Russia \\ ${ }^{2}$ Petrozavodsk State University, Lenina 33, 185910, Petrozavodsk, Russia
}

\begin{abstract}
The objective of the article is to analyze the number of employees aggregated in the mass media and content sector in Russia for the period from 2010 to 2019. Mass media and content sector is one of the sectors which is developed very dynamically at the present time. Since rural people do not possess high-skill professional skills and competencies at the present time, the IT sector is excluded from the analysis. With the help of prior research of competencies and skills of rural people we also made the forecast of the most appropriate sector to produce services online. Then thanks to prior research about goods and services on demand in Russian e-commerce, we elaborated the list of services which rural people can produce and sell remotely with the help of Internet. This primary list recap services which almost anu individual can produce. But to be capitalized they need to be branded and advertised appropriately.
\end{abstract}

\section{Introduction}

As far as Russian rural communities and rural people still suffer from unemployment and lack of government support in order to provide better quality of life, better ecological conditions for life, we see that the strategy of endogenous development would be the most viable one. It does not mean that rural territories does not need any financial support from the government, but it means that there are some steps rural community can implement to attract government or non-commercial organizations to its problems and get finances to resolve problems in need.

Nevertheless, the problems of employment and social infrastructure are the most vivid today for rural community, we have to admit that the problem the environmental problems also exist. Unfortunately, since high-priority problems are to be resolved, others stay untouched. On the other hand, from our prior research we see that rural community tries to maintain its territory clean and organize different ecological events. We see that environmental conditions of their territory are important for the community and local struggle for it by means they dispose. That is why we suppose that the most important goal for rural community at the present time stays the problem of unemployment. We argue that

\footnotetext{
${ }^{*}$ Corresponding author: a7830298@gmail.com
} 
employed people with good salary can find much more options to protect their territory and to attract finances for environmental issues.

The objective of this paper is to revise the number of employees aggregated in the sector of mass media and content services at its whole and subdivided into four main types of services and to propose the most appropriate and viable market niches for rural locals to produce and sell on-line services remotely.

\section{Literature review}

We agree that there is the "linear relation between environmental degradation and income" in developing countries, as assume T. A. Masron and Y. Subramaniam [1]. L. Christiaensen and al. [2] found that the development of agriculture works better and more efficiently for poverty eradication. We argue that not only agricultural products, but some sorts of nonimportable, as it is proposed by Van der Ploeg et al. [3] with the help of preserving cultural authenticity, proposed by Ray C. [4] can be a product at the era of digitalization. J. R. Anderson [5] also points out the need in investment into the knowledge of farmers to prevent the environment degradation.

We assume that with the rise of entrepreneurial activity the environmental problems can be solved from the bottom by local people. That is why we maintain the idea of remote work and remote entrepreneurial activity due to digitalization. For example, « lifestyle entrepreneurship » considered successful by Cunha C. et al. [6] gives local people an opportunity to start working remotely in accordance with their competencies, skills, interests and resources. On the others side, as it is found in the researches of Fedorova M. Yu. and Aleksandrov I.N. [7] locals do not aware of tools and ways to earn money with the help of Internet.

According to Boland, M., Ivus, O. the broadband deployment affects positively on the development of services, especially, IT services in rural areas [8]. Surely, retail sector is believed to be one of the most perspective in tertiary sectors in the digital economy, but as it was found in the research of G20 "internet users make purchases online more than they are engaged in selling" [9].

As we see in the research Kolko J. [10] the specialists in IT sector depend on the development of the Internet most of all. At the same time, managerial services for big companies, research, technological and informational services also positively depend on the development of the Internet in rural areas. But Kolko J. did not find the dependance of the educational, health, social services, art and entertainment on the Internet development [10].

Talking about the employment we have to take in mind present digital conditions, which, we argue, play the core role in creating new jobs opportunities for rural people. That is why the objective of our research is to find out new job opportunities for rural people in the digital economy.

D. H. Autor, D. Dorn [11] show the rise of the service occupation and wages for the period from 1980 to 2005 in the USA. It should be mentioned that, as a rule, the service occupation was made of noncollege workers. The author also say that the service occupation is difficult to automate. In that case we should add that at the present time many services on demand need Internet.

We also see that in the framework of endogenous theory the concept of "place branding", proposed by Guinjoan E. et al. [12] or "cultural economy", proposed by Ray C. [4] is believed to be the most viable one in the framework of digitalization if we are talking about producing and selling "non-importables" described by J. D. van der Ploeg and al. [3] and that need to possess cultural authenticity. 
That is why we suppose that, firstly, there are type of services which can be produced and transferred with the help of Internet, so rural territories can provide them. Another hypothesis is that those services are not low-skill, but medium-skill.

\section{Methodology}

The research was implemented with the help of the statistical data on the Russian informational society gathered for the period from 2010 to 2019 and for the period from 2005 to 2019 for different types of services by the Russian Higher School of Economy [1316]. The data covers numbers about the total number of Mass Media and Content Industries' employees, then its segregation according to four types of Mass Media and Content major activities according to the State Russian Classification System.

We used only Mass Media and Content Industry in our research because of its high grow among other activities on the Internet. The IT sector was excluded from the research due to its high-skilled demand on the employees. And our previous research [7] shows that locals do not possess needed high-skill entrepreneurial or professional competencies to work remotely. That is why we argue that for rural locals other service sectors should be chosen in order to find appropriate type of remote work or business.

\section{Research}

According to the Figure 1 we see that the total number of Mass Media and Content Industries rises from 2005 constantly. The year 2008 was the year of the crisis start and we see insignificant decline. On the other hand, as far as the period from 2008 to 2015 can be described by its even minor decline we can name it also as the stagnation, which is also not the profitable one. But we also see the sharp rise from 2015 which once consequences by decline and then the rise.

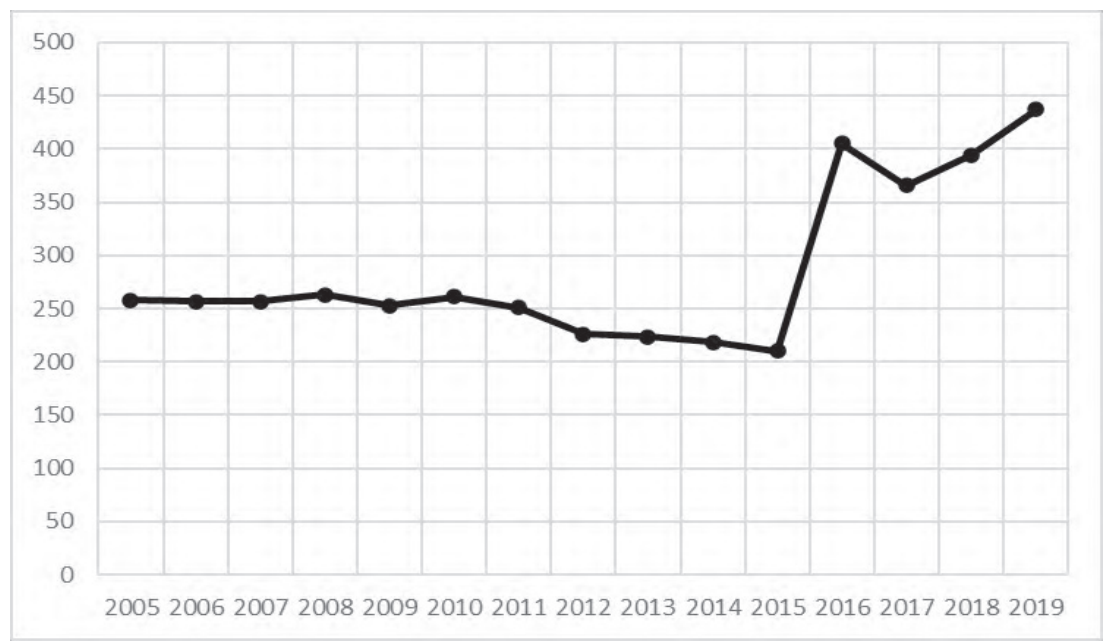

Fig. 1. Total number of Mass Media and Content Industries' employees in Russia for the period 2005 - 2019, thousands of people (source: elaborated by the authors).

Looking at the Figure 2 we also can see the segregation to four activities in the sector of Mass Media and Content. We see that the highest number of employees are aggregated in the sector of publishing. The number of employees aggregated in TV and Broadcasting services is also high but in comparison with Publishing activities it is declining at the 
moment. The number of employees providing the services of information agencies are not the highest, but the important thing is that the number in that sector is constantly rising. That is why that is the most interesting type of activity we want to revise for rural locals be involved in.

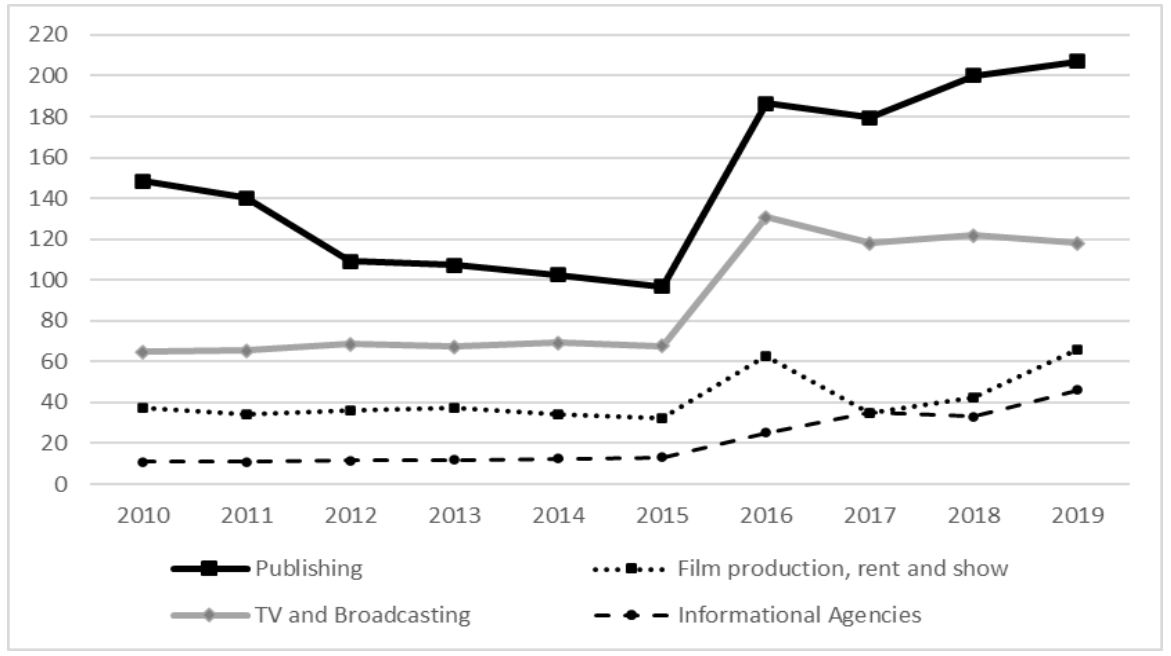

Fig. 2. Number of employees in Mass Media and Content Industries in Russia, by the economic activity, for the period $2010-2019$, thousands of people (source: elaborated by the authors).

At the Figure 3 we can see the forecast for the sector providing informational and other services. According to the forecast the number of employees is going to rise, even in case of low probability. It should be mentioned that the case of low probability proposes only low rise of employees aggregated in this sector, nut nevertheless the number is positive. At the same time, we admit that in case of economic crises the competitiveness becomes more tough in all sectors, including informational services, that is why rural employees need possess competencies to struggle for their job or business.

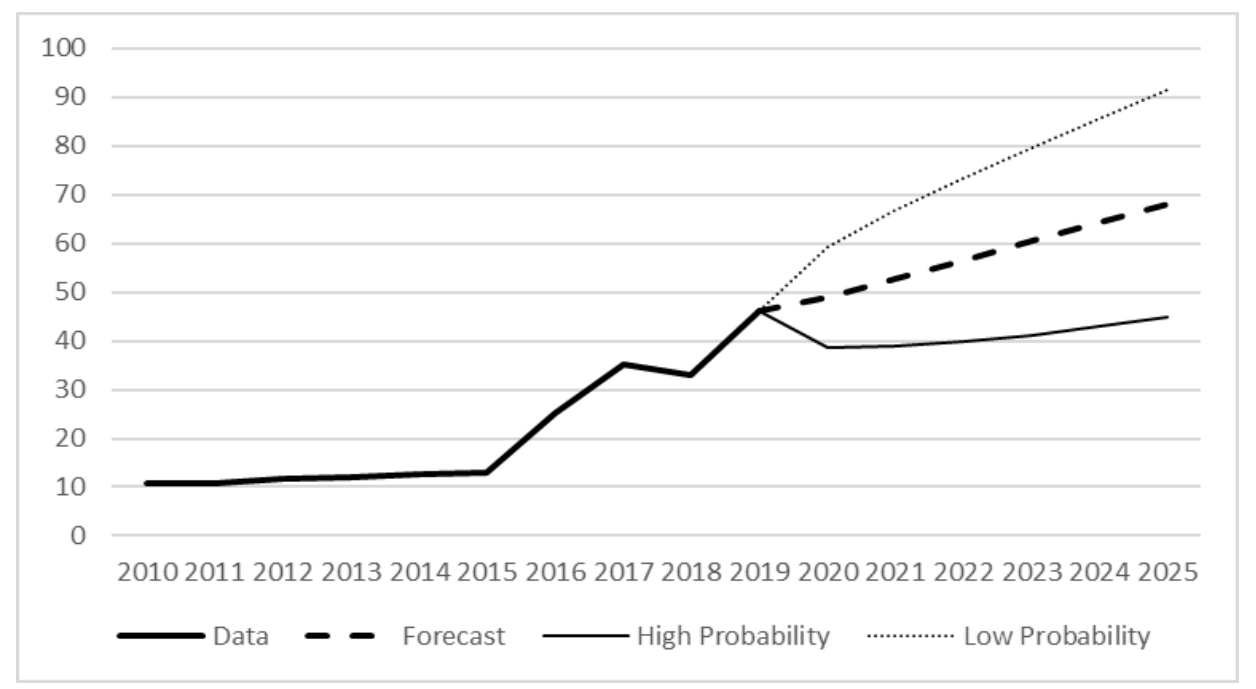

Fig 3. Forecast for number of employees in Russian Information agencies and other services thousands of people (source: elaborated by the authors). 


\section{Discussion}

We see that the number of employees in the sector of Informational agencies and other informational services are going to rise what makes us to believe that kind of job can be appropriate for rural locals to work remotely.

Table 1. Market niches to sell remotely in the digital economy.

\begin{tabular}{|c|c|c|c|}
\hline Sector & Type of services & $\begin{array}{l}\text { Advertising on the } \\
\text { Internet }\end{array}$ & $\begin{array}{l}\text { Selling on the } \\
\text { Internet }\end{array}$ \\
\hline \multirow{3}{*}{ Nutrition } & Cuisine courses and workshops & + & + \\
\hline & $\begin{array}{l}\text { Authentic cuisine courses and } \\
\text { workshops }\end{array}$ & + & + \\
\hline & $\begin{array}{l}\text { Workshops for long-term storage } \\
\text { products }\end{array}$ & + & + \\
\hline \multirow{4}{*}{ Kids' services } & Educational services & + & + \\
\hline & Extra educational services & + & + \\
\hline & On-line leisure activities for kids & + & + \\
\hline & Art courses and workshops for kids & + & + \\
\hline Pets' service & Consultancy on pets' care & + & + \\
\hline \multirow{3}{*}{ Clothes and shoes } & $\begin{array}{l}\text { Clothes and shoes making courses } \\
\text { and workshops }\end{array}$ & + & + \\
\hline & $\begin{array}{l}\text { Knitting and making leather shoes } \\
\text { courses and workshops }\end{array}$ & + & + \\
\hline & $\begin{array}{l}\text { Making authentic costumes courses } \\
\text { and workshops }\end{array}$ & + & + \\
\hline \multirow{5}{*}{ Beauty } & $\begin{array}{l}\text { Making homemade cosmetics } \\
\text { courses and workshops }\end{array}$ & + & + \\
\hline & $\begin{array}{c}\text { Face and body skin care courses } \\
\text { and workshops }\end{array}$ & + & + \\
\hline & $\begin{array}{c}\text { Face massage courses and } \\
\text { workshops }\end{array}$ & + & + \\
\hline & Fitness & + & + \\
\hline & $\begin{array}{c}\text { Beauty photo courses and } \\
\text { workshops }\end{array}$ & + & + \\
\hline $\begin{array}{l}\text { Construction } \\
\text { materials }\end{array}$ & Construction materials consultancy & + & + \\
\hline \multirow{2}{*}{ Car parts } & Car repair consultancy & + & + \\
\hline & Car maintenance consultancy & + & + \\
\hline Goods for home & Handmade workshops and courses & + & + \\
\hline
\end{tabular}

According to our previous research about e-commerce in Russia and the demand on different types of products and services [17] and taking in mind the lack of information among rural locals about economic niches to start from, we elaborated the sample of job types for rural people to start work remotely or to start their own business (Table 1). The Table 1 shows what kind of services rural people can provide remotely in accordance with their professional skills and interests.

We see that such kind sectors as quality nutrition, kids services for pets, quality and unique clothes and shoes, different kinds of beauty services, services connected with construction materials and car parts and different goods for home, which are unique and possess their intangible characteristics are on demand at the present time. Those intangible characteristics can be acquired with the help of branding which can be especially unique for rural territories preserving their cultural heritage and human capital.

We also have to take in mind that people from big cities are very time-pressed that is why on-line consulting services, courses and workshops for them are the reality which is 
now very usual even for small kids, who study as major educational subjects as also extra subjects to deeper their knowledge or to entertain or to broaden its horizon. Another reason why on-line courses, workshops and consulting services are in need now is that we face problems of epidemies such Covid-19, for example. We do not know how often we are going to solve problems like this and to stay at home for a long time. But the need to be educated and entertained do not disappear but rise in such new reality. The case with Covid-19 made consumers get more used to on-line educational services. At the same time providers of those services understood that they need more efficient competencies in the sector of on-line education.

\section{Conclusion}

The statistical data research of Russian mass media employees shows its rise, especially for the last period. One of the main reasons is the digitalization and Internet deployment not only in big cities but in rural areas also. Due to this fact the thorough analysis of this sector was implemented. According to the analysis of four main sectors, such as publishing, TV and broadcasting, production, rent and show of films and informational and other services the last position shows the most constant grow, nevertheless the highest data on employees in those sectors is the number of employees aggregated in publishing. Taking into account our prior research about entrepreneurial and professional skills and competencies of rural people and investments to be done to start entrepreneurial activity in publishing, or producing films or TV and broadcasting, we exclude those sectors rural people could be involved in large-scale. The sector of informational resources was elaborated into the list of preliminary services rural people could produce and sell remotely to start their own entrepreneurial activity or start working remotely. We assume that that will help people earn more money and become more resilient to economic volatility. The more resilient and wealthier locals are, the more they care about the environment by themselves from the bottom.

\section{References}

1. T. A. Masron, Y. Subramaniam, Does Poverty Cause Environmental Degradation? Evidence from Developing Countries, Journal of Poverty 1-24, (2018) DOI: 10.1080/10875549.2018.1500969

2. L. Christiaensen, L. Demery, J. Kuh. The Role of Agriculture in Poverty Reduction An Empirical Perspective (RePEc, 2006) DOI: 10.1596/1813-9450-4013

3. J.D. Van Der Ploeg, H. Renting, G. Brunori, K. Knickel, J. Mannion, T. Marsden, K. D. Roest, E. Sevilla-Guzmán, F. Ventura, Rural Development: From Practices and Policies towards Theory, Sociologia Ruralis 40 (4), 391-408 (2000) DOI: 10.1111/1467-9523.00156

4. C. Ray, Culture Economies: a perspective on local rural development in Europe, Centre for Rural Economy, Dept. of Agricultural Economies and Food Marketing (2001)

5. J. R. Anderson, Environmental Issues and Farming in Developing Countries, (RePEc, 2002)

6. C. Cunha, E. Kastenholz, M. J. Carneiro, Entrepreneurs in rural tourism: Do lifestyle motivations contribute to management practices that enhance sustainable entrepreneurial ecosystems?, Journal of Hospitality and Tourism Management 44, 215-26 (2020) 
7. M. Fedorova, I. Aleksandrov, Digital economy and green economy: rural unemployment and territorial self-development in Russia, E3S Web of Conferences 110, 02019 (2019) https://doi.org/10.1051/e3sconf/201911002019

8. M. Boland, O. Ivus, The Employment and Wage Impact of Broadband Deployment in Canada, Canadian Journal of Economics 48(5), 1803-30 (2015)

9. Tolkit for measuring the digital economy, G20. Argentina, 2018 URL: https://www.itu.int/en/ITU-D/Statistics/Documents/g20-detf-toolkit_FINAL.pdf

10. J. Kolko, Broadband and local growth, Journal of Urban Economics 71(1), 100-13 (2011)

11. H. Autor, D. Dorn, The Growth of Low-Skill Service Jobs and the Polarization of the US Labor Market, American Economic Review 103(5), 1553-97 (2013)

12. E. Guinjoan, A. Badia, A.F. Tulla, The new paradigm of rural development. Theoretical considerations and reconceptualization using the "rural web", Boletín de la Asociación de Geógrafos Españoles 71, 495-500 (2016)

13. Statistic Data on the Russian Content and Mass Media Sector on the period from 2005 to 2010

https://www.hse.ru/data/2017/08/02/1173493136/IIO\%202017.\%203.\%20Sektor\%20k ontenta $\% 20 i \% 20$ SMI.pdf

14. Indicators of the Digital Economics: 2019 URL: https://www.hse.ru/data/2019/06/25/1490054019/ice2019.pdf

15. Indicators of the Digital Economics: 2020 URL: https://issek.hse.ru/mirror/pubs/share/387609461.PDF

16. Indicators of the Informational Society: 2016 URL: https://www.hse.ru/data/2016/03/14/1124859837/\%D0\%98\%D0\%BD\%D0\%B4\%D0\% B8\%D0\%BA\%D0\%B0\%D1\%82\%D0\%BE\%D1\%80\%D1\%8B\%20\%D0\%B8\%D0\%B D\%D1\%84\%D0\%BE\%D1\%80\%D0\%BC\%D0\%B0\%D1\%86\%D0\%B8\%D0\%BE\%D 0\%BD\%D0\%BD\%D0\%BE\%D0\%B3\%D0\%BE\%20\%D0\%BE\%D0\%B1\%D1\%89\%D 0\%B5\%D1\%81\%D1\%82\%D0\%B2\%D0\%B0\%202016.pdf

17. M. Fedorova, I. Aleksandrov, A. Parshukov, E-commerce in Russian rural areas as a tool for regional development, E3S Web of Conferences. INTERAGROMASH 175, 13046 (2020) DOI: 10.1051/e3sconf/202017513046 